\title{
Educación, Patria y progreso: las escuelas de primeras letras en el Caribe colombiano, 1820-1828
}

Roger Pita Pico*

Recibido: abril de 2014

Aprobado: agosto de 2014

Resumen: Este artículo analiza la fase de implementación de las escuelas primarias en la costa Caribe colombiana a partir del impulso dado por las leyes y decretos dictados en 1820 y 1821. Se intenta demostrar cómo, frente a los fracasos y disputas experimentadas durante la Primera República Federativa, el gobierno central buscó hacer presencia y ganar legitimidad a nivel regional a través de estrategias como el fomento de las escuelas primarias, instituciones consideradas como vitales para el progreso y el proceso de recuperación económica. Para alcanzar esa meta, el ejecutivo nacional cedió algunas responsabilidades a las autoridades locales pero manteniendo el control y la vigilancia. Estos establecimientos educativos se convirtieron también en escenarios a través de los cuales se buscó inculcar los principios republicanos y patrióticos con miras a mantener la unidad y estabilidad del sistema político. No obstante, este proyecto encontró en el ámbito regional

* Politólogo de la Universidad de los Andes, Especialista en Gobierno Municipal, Especialista en Política Social, Magíster en Estudios Políticos de la Pontificia Universidad Javeriana, Miembro de Número de la Academia Colombiana de Historia y director de la Biblioteca "Eduardo Santos" de la Academia Colombiana de Historia. rogpitc@hotmail.com

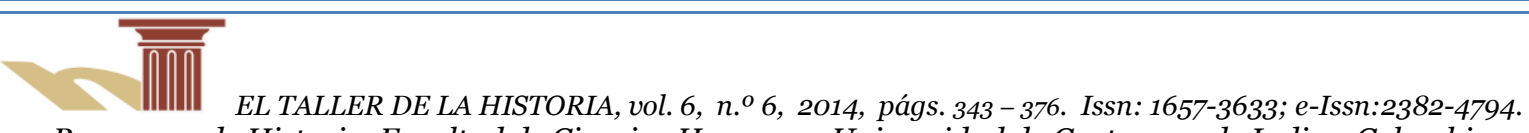
Programa de Historia, Facultad de Ciencias Humanas, Universidad de Cartagena de Indias, Colombia 
de la costa Caribe varios obstáculos, tales como: la crisis fiscal y económica, el efecto destructor de la guerra y el débil aparato administrativo a lo cual había que sumarle las limitadas oportunidades de inclusión para algunos sectores de la sociedad.

Palabras claves: educación, escuelas primarias, Patria, Caribe colombiano, República.

\title{
Education, homeland and progress: the schools of letters in the Colombian Caribbean, 1820-1828
}

\begin{abstract}
This paper analyzes the implementation phase of the primary schools in the Colombian Caribbean coast from the impetus provided by the laws and decrees issued in 1820 and 1821. The objective of this research is to show how, with the failures and disputes experienced during the First Federal Republic, the central government sought to make regional presence and gain legitimacy through strategies such as the promotion of primary schools, institutions considered vital to the progress and the economic recovery. To achieve this goal, the national executive gave some responsibilities to local authorities while maintaining control and monitoring. These educational institutions also became scenarios through which Republicans sought to instill patriotic principles in order to maintain the unity and stability of the political system. However, this project stumbled at the regional level of the Caribbean coast several obstacles, such as fiscal and economic crisis, the destructiveness of war, weak administrative apparatus and the limited opportunities of social inclusion.
\end{abstract}

Key words: education, primary schools, patriotism, Colombian Caribbean, Republic. 


\section{Introducción}

Las escuelas no fueron una prioridad para el gobierno español durante el periodo colonial. La mayoría de estos establecimientos fueron fundados por conventos y algunos pocos eran anexos a los colegios. Entre tanto, las escuelas de carácter privado eran en realidad muy escasas. ${ }^{1}$

Durante la Primera República Federativa, la provincia de Cartagena había logrado mayores avances en materia educativa que la vecina provincia de Santa Marta en razón a que en aquella habían gobernado los republicanos con relativa estabilidad mientras que en esta los españoles mantuvieron por más tiempo su poderío siendo más evidente allí el efecto desolador de la lucha independentista y el caos social y económico.

En el artículo $1^{\circ}$ del título XII de la Constitución del Estado de Cartagena de Indias promulgada en 1812, se planteó la importancia de la educación por cuanto era "[...] la que mejor iguala a todos los ciudadanos, les inculca y hace amables sus deberes, aumenta la propiedad individual y las riquezas del Estado, suaviza las costumbres y en gran manera mejora y previene los delitos". ${ }^{2}$ El propósito con estas medidas era alejar a la "tierna juventud" de ambos sexos del ocio y de los vicios. Se concibió también la escuela como un espacio propicio para perfeccionar el sistema de gobierno republicano y difundir los hitos fundacionales de la Patria. ${ }^{3}$

En el artículo $2^{\mathrm{O}}$ se habló específicamente de tomar las medidas pertinentes “[...] para el establecimiento de escuelas de primeras letras en todos los poblados, y se perfeccionarán éstas conforme se proporcionen los fondos necesarios para competentes dotaciones; debiendo ser los objetos de su enseñanza la doctrina cristiana, los derechos y deberes del ciudadano, leer, escribir, dibujar y los primeros elemen-

1 Evelyn Ahern, "El desarrollo de la educación en Colombia: 1820-1850", en Revista Colombiana de Educación n. ${ }^{\circ}$ 22-23, Bogotá, Universidad Pedagógica Nacional, 1991, pp.17-21.

2 Constitución del Estado de Cartagena de Indias, Cartagena de Indias, Imprenta del Ciudadano Diego Espinosa, 1812, pp.111-112.

3 Rafael E. Acevedo, "La historia y la patria en la provincia de Cartagena, 1810-1814. Apuntes sobre la noción de usos públicos de la historia”, en Memoria y Sociedad vol.14, n. ${ }^{\circ} 29$, Bogotá, Pontificia Universidad Javeriana, 2010, pp.16, 20. 
tos de la geometría". ${ }^{4}$ Estos avances constitucionales terminaron truncados en 1815 cuando los españoles recuperaron el poder político por la vía militar.

En 1819, cuando los republicanos lograron instalarse de nuevo en el gobierno, una de sus prioridades fue concentrarse en el impulso de la educación elemental. Pese al entusiasmo inicial liderado por el vicepresidente Francisco de Paula Santander, fueron muchos los percances que se interpusieron para el logro de esta meta. Al principio, la ampliación de este nivel educativo comenzó a implementarse en la zona andina central ya liberada pero el proceso fue más demorado en aquellos espacios aún en disputa como la región del Cauca, Pasto y la Costa Caribe. Como bien se sabe, Santa Marta solo pudo ser liberada en noviembre de 1820 mientras que Cartagena lo logró en octubre del año siguiente.

El 6 de octubre de 1820 el vicepresidente Francisco de Paula Santander dictó un decreto que es considerado el primer plan de educación primaria. Allí se reconoció que la instrucción pública era el medio más fácil para que los ciudadanos asimilaran sus derechos y deberes en sociedad, siendo responsabilidad del Estado asegurarles la educación para contribuir a su bienestar y felicidad. Los maestros debían enseñar a los niños a leer, escribir y contar, y además explicar los dogmas de la religión y de la moral cristiana. Como todavía en estos tiempos la República libraba estrategias para defender los territorios emancipados y para expulsar a los españoles de algunas zonas de territorio de la República, se ordenó que los niños debían recibir enseñanza militar los jueves en la tarde y los días de fiesta. ${ }^{5}$ Con este decreto, el gobierno abrigaba la esperanza de que las ciencias, las artes, la agricultura y la industria progresaran a medida que el hábito de la lectura, la escritura y la aritmética se hicieran más comunes. ${ }^{6}$

4 Constitución del Estado de Cartagena, p.112.

5 Felipe Osorio Racines, Decretos del General Santander. 1819-1821, Bogotá, Universidad Nacional, 1969, p.154.

6 Alejandro Osorio y Estanislao Vergara, Los encargados de la Secretaría General del Departamento de Cundinamarca presentan a S. E. el General F. de P. Santander, vicepresidente del mismo Departamento, la memoria correspondiente al año de 1820, Bogotá, Imprenta de Espinosa, 1821, p.46. 
En la Constitución de la República de Colombia, promulgada en 1821, se contemplaron una serie de atribuciones especiales al Congreso para la promoción de la educación pública. ${ }^{7}$ En respuesta a este mandato, el Congreso de Cúcuta dictó la ley del 2 de agosto que autorizó al poder ejecutivo para que en las principales ciudades fueran creadas escuelas pilotos con el método lancasteriano o de enseñanza mutua, ${ }^{8}$ para que de allí se fueran difundiendo a todas las provincias. ${ }^{9} \mathrm{Al}$ cabo de dos meses, esta ley fue publicada en las páginas de la Gazeta de Santa Marta. ${ }^{10}$

El presente artículo tiene por objeto analizar los avances y retrocesos de la fase de implementación de las escuelas primarias en la costa Caribe colombiana a partir del impulso dado por las mencionadas leyes dictadas en 1820 y 1821 . Sobre estos primeros años de la Segunda República, etapa clave en el proceso de formación nacional, se han elaborado algunos trabajos que tratan el tema de una manera panorámica para el territorio de Colombia, razón por la cual con este artículo se pretende llenar un vacío concentrando la investigación en el caso concreto de la costa Caribe.

En este contexto, se intenta demostrar cómo, frente a los fracasos y disputas experimentadas durante la Primera República Federativa, el gobierno central buscó hacer presencia y ganar legitimidad a nivel regional a través de diferentes estrategias, siendo una de ellas el fomento de las escuelas primarias de carácter público, consideradas como vitales para el progreso y el proceso de recuperación económica posterior a las guerras por la Independencia. Para alcanzar esa meta, el ejecutivo nacional cedió algunas responsabilidades a las autoridades locales pero mante-

7 Constitución de la República de Colombia, Rosario de Cúcuta, Bruno Espinosa, Impresor del Gobierno General, 1821, p.22.

8 José Lancáster era un pedagogo inglés cuyo método de enseñanza, conocido también con el nombre de mutua instrucción, consistía en que un solo maestro pudiera dirigir a un gran número de alumnos debiendo estos colaborarle activamente en esta labor. Véase: Francisco Sanabria Munévar, "Enseñando mutuamente: una aproximación al método lancasteriano y a su aprobación en Colombia”, en Revista Historia de la Educación Colombiana vol.13, n. ${ }^{\circ} 13$, Pasto, Rudecolombia, 2010, pp.47-76.

9 Actas del Congreso de Cúcuta, 1821, Bogotá, Biblioteca de la Presidencia de la República, 1990, vol.II, pp. 59, 160.

10 "El Congreso General de la República”, en Gazeta de Santa Marta n. ${ }^{\circ} 23$, Santa Marta, Imprenta del seminario por Tadeo Rodríguez, octubre 13 de 1821, pp.89-91. 
niendo un control más directo que el ejercido por el gobierno colonial en los tiempos del dominio hispánico. Estos establecimientos educativos se convirtieron también en escenarios a través de los cuales se buscó inculcar los principios republicanos y el sentimiento patriótico con miras a mantener la unidad y estabilidad del sistema político recién establecido.

No obstante, este proyecto encontró en el ámbito regional de la costa Caribe un sinnúmero de obstáculos, tales como: la crisis fiscal y económica, el efecto destructor de la guerra y el débil aparato administrativo a lo cual había que sumarle las limitadas oportunidades de inclusión para algunos sectores de la sociedad.

Para profundizar sobre estos planteamientos fue necesario tener como base sustancial de información las fuentes primarias de archivos documentales, las cartas, los informes de gobierno, las leyes y decretos y la prensa de la época que fue sin duda un espacio de discusión y reflexión sobre la importancia de la cultura y la instrucción pública. Todo esto complementado con el acervo de propuestas, solicitudes y quejas registradas a nivel local y regional.

El tema de las escuelas de primeras letras para el periodo objeto de este estudio ha adquirido un especial interés en el debate historiográfico latinoamericano de cara a la celebración del bicentenario de la Independencia y el surgimiento de los Estados republicanos, notándose un especial énfasis en examinar la implantación de escuelas con el método lancasteriano. ${ }^{11}$

El denominador común de los estudios alusivos al territorio del Caribe colombiano ha sido la relación estrecha entre educación y cultura política donde es claro ver cómo la esfera de lo político permeó de una manera notoria el diseño y las políticas de expansión de la educación pública. Algunas de las investigaciones recientes han tratado de indagar sobre el desarrollo de las escuelas en las décadas siguientes al periodo propuesto en este artículo, ${ }^{12}$ lo cual abre campo para futuros

11 Véase por ejemplo: Dorothy Tranck de Estrada, "Las escuelas lancasterianas en la ciudad de México”, en La educación en la historia de México, México, El Colegio de México, 1992, pp.49-68.

12 Véanse: Ángel Rinaldy, "Nación moderna: ciudadanos letrados. El compromiso de la élite cartagenera en la educación popular durante la República 1820-1840", en Historia Caribe vol.vI, n. ${ }^{\circ} 19$, Barranquilla, Universidad del Atlántico, 2011, pp.153-175; Luis Alarcón Meneses, "Maestros y escuelas normales en el Caribe colombiano durante el régimen federal", en Revista Historia de la Educa- 
ejercicios comparativos que permitan construir una visión más integral sobre el avance de este nivel educativo en la región.

\section{Retos en cobertura}

En el antiguo régimen hispánico, el acceso a la educación era muy limitado y, de algún modo, reflejaba las desigualdades sociales y étnicas. ${ }^{13}$ Aunque la pretensión del gobierno republicano era cambiar drásticamente este desolador panorama a través de la masiva fundación de escuelas en todas las poblaciones, en términos reales esa era una meta difícil de alcanzar, especialmente en estos tiempos de posguerra en que apenas se realizaban ingentes esfuerzos con miras a la recuperación económica.

El decreto del 6 de octubre de 1820 dictado por el vicepresidente Santander y la ley del 2 de agosto de 1821 promulgada por el Congreso de Cúcuta lanzaron algunas fórmulas en el intento por lograr resultados concretos y alcanzables en materia de cobertura.

No hay que olvidar que la región Caribe tardó mucho más tiempo en expulsar a los realistas. A pesar de la devastación derivada de la guerra, pronto empezaron a verse algunos progresos. Cartagena fue la primera ciudad del departamento del Magdalena ${ }^{14}$ en abrir escuela bajo el nuevo método de enseñanza gracias a las gestiones adelantadas por Pedro Comettan, ${ }^{15}$ quien llegó a la ciudad en agosto de

ción Latinoamericana vol.14, n. ${ }^{\circ} 18$, Tunja, Universidad Pedagógica y Tecnológica de Colombia, 2012, pp.155-182; Rafael Acevedo, "Escuelas y políticas educativas en la provincia de Cartagena entre 1903-1919", en El Taller de la Historia vol.3, n. ${ }^{\circ}$, Cartagena, Universidad de Cartagena, 2011, pp.110-135.

13 E. Ahern, "El desarrollo de la educación", p.21.

14 Según la división político-administrativa fijada por el decreto oficial dictado el 23 de junio de 1824, el departamento del Magdalena tenía como capital la ciudad de Cartagena y comprendía las provincias de Cartagena, Santa Marta y Riohacha, es decir, cubría prácticamente toda la costa Caribe colombiana.

15 Este francés fue traído a América por el secretario de Relaciones Exteriores, José Rafael Revenga, con el fin de enseñar y formar maestros con el método lancasteriano. Inicialmente fue destinado 
1822 y durante cinco meses dirigió el proceso de montaje y capacitación de maestros. 16

En respuesta al requerimiento hecho por el vicepresidente Santander, la intendencia del departamento del Magdalena elaboró en octubre de 1823 un informe que daba cuenta del cubrimiento de la educación primaria en su territorio. Mompós y Cartagena ya tenían instaladas escuelas lancasterianas. En esta última ciudad se hallaban registradas dos más por el método antiguo: la de Trinidad y la de Santo Toribio. En el cantón de Barranquilla existían dos escuelas, una de ellas en la ciudad del mismo nombre y otra en Tubará, ambas por el método antiguo, siendo sus profesores el presbítero Nicolás Insignares y Nicolás Vargas, respectivamente. Una escuela por el método antiguo funcionaba en la ciudad de Ocaña y otra de este mismo método en la población de Lorica bajo la batuta del profesor Vicente García. El presbítero Ramón Laguna era el maestro de la escuela del método antiguo fundada en junio de 1822 en Santa Marta, plantel que debió ser cerrado el 3 de enero de 1823 a causa de la tensión militar y la crítica situación económica. Con el ánimo de restablecer en esta ciudad el servicio educativo, sus autoridades enviaron un maestro a la ciudad de Cartagena para que se capacitara en el sistema lancasteriano. $\mathrm{Al}$ momento del informe, Riohacha tampoco contaba con escuela debido al caos que provocó allí un voraz incendio y porque todos los esfuerzos estaban concentrados en la defensa militar de la ciudad que aún estaba amenazada por las fuerzas españolas que mantenían el dominio sobre Maracaibo. De los cantones de Soledad, Corozal, Magangué y Valledupar no se reportó la existencia de ninguna escuela. En síntesis, para octubre de 1823 solo se contabilizaron en la región Caribe ocho escuelas, dos de ellas por el método lancasteriano. ${ }^{17}$

a fundar la escuela normal de la ciudad de Caracas y viajó luego con el mismo propósito a Maracaibo, Cartagena y Panamá, contando siempre con el apoyo del gobierno republicano. Luis López Domínguez (comp.), Obra educativa de Santander 1819-1826, vol.I, Bogotá, Biblioteca de la Presidencia de la República, 1990, pp.56, 68, 170 y 246.

16 Archivo General de la Nación (AGN), Sección República, Ministerio de Instrucción Pública, tomo 109, ff.625r.-626r. (Cartagena, 1822).

17 AGN, Sección República, Ministerio de Instrucción Pública, tomo 109, ff.675r.-701r. (Cartagena, 1823). 
A principios de 1824, en la prensa regional salió publicado un aviso dirigido a los padres de familia que, debido a la larga distancia, les resultaba difícil enviar sus hijos hasta la escuela de la ciudad de Cartagena. A ellos se les informó la grata noticia de que en adelante podían contar con una nueva opción que era la escuela de enseñanza mutua fundada en marzo de 1823 en Mompós, gracias a la instrucción impartida por Pedro Comettan durante el tiempo de convalecencia que debió pasar en esta villa. ${ }^{18}$ La escuela fue costeada por la municipalidad y por varios vecinos "amantes de la ilustración”. Su profesor era Nicolás Villar y su director el alcalde ordinario Francisco Trespalacios. ${ }^{19}$

En la villa de Soledad se fundó escuela en septiembre de $1824^{20}$ y al cabo de un mes se inauguró una nueva en la parroquia de Ciénaga de Oro. ${ }^{21} \mathrm{El} 5$ de enero del año siguiente se abrió un plantel educativo en la población de Turbaco con 80 pequeños listos para iniciar clases y el 10 de abril abrió sus puertas la escuela de la parroquia de Turbana, gracias a la diligente gestión del juez político del cantón, Francisco de Paula Herrera. Con el modelo antiguo, funcionaban escuelas en Tubará y Chinú. ${ }^{22}$

Según la prensa oficial, para mediados de 1824 varios los pueblos de la provincia de Santa Marta ya tenían instalada su escuela pública pero en la capital, Santa Marta, no se había conseguido aún un sujeto capaz de desempeñar las funciones de director a pesar de los reiterados avisos a nivel local ante lo cual fue necesario publicar un anuncio en la gaceta nacional. Hacia finales de este año se estableció

18 AGN, Sección República, Fondo Ministerio de Instrucción Pública, tomo 106, f.78r. (Mompós, 1823).

19 “Aviso a los pueblos”, en Gaceta de Cartagena de Colombia n. ${ }^{\circ} 129$, Cartagena, Imprenta del Gobierno por Juan Antonio Calvo, enero 31 de 1824, p.538.

20 “Aviso al público", en Gaceta de Cartagena de Colombia n. ${ }^{\circ} 157$, agosto 14 de 1824, p.4.

21 “Provincia de Cartagena”, en Gaceta de Cartagena de Colombia n. ${ }^{\circ}$ 175, diciembre 18 de 1824, p.2.

22 "Departamento del Magdalena", en Gaceta de Colombia, n. ${ }^{\circ} 175$, Bogotá, Imprenta de Espinosa, febrero 20 de 1825, p.3; Gaceta de Cartagena de Colombia, n. ${ }^{\circ} 195$, mayo 7 de 1825, p.3. 
escuela bajo el nuevo método en Riohacha ${ }^{23}$ y en Ocaña se inauguró otra a principios de $1825 \cdot{ }^{24}$

Estos eran avances significativos para la región, especialmente por la posibilidad de extender en poco tiempo los beneficios de la educación elemental a muchas más poblaciones en lugares apartados de la región, con lo cual se apuntaba a generar nuevas oportunidades de desarrollo socio-económico y a contrarrestar el monopolio que desde tiempos coloniales habían ejercido Cartagena y Mompós en materia educativa y cultural.

Sin embargo, notorios contrastes se registraban con otras zonas de la República, como en el caso de la zona andina central que mantuvo los más altos índices de expansión de la educación primaria. Así por ejemplo, un total de 105 escuelas se hallaban funcionando en 1824 en el departamento de Boyacá que por ese entonces comprendía las provincias de Tunja, Socorro, Pamplona y Casanare. ${ }^{25}$

Además de los planteles públicos impulsados por el gobierno, en ocasiones surgió la iniciativa de algunos profesores de montar su propio establecimiento educativo de carácter privado. ${ }^{26} \mathrm{El}$ señor David Rosa, proveniente de la isla de Jamaica, promocionó a comienzos de 1825 a través de las páginas de la Gaceta de Cartagena de Colombia un método efectivo y rápido para aprender a escribir en un mes y con "hermosa" letra. Su sistema lo creía aplicable incluso para personas de avanzada edad y aseguró tener unos costos moderados con la opción de enseñar en su casa o brindar el servicio a domicilio. ${ }^{27}$ Semanas más tarde, el profesor Andrés Ballon promocionó en esa misma ciudad la puesta en funcionamiento de una escuela de instrucción dirigida a niños de ambos sexos, para lo cual puso de presente su com-

23 “Aviso", en Gaceta de Cartagena de Colombia, n. ${ }^{\circ}$ 174, diciembre 11 de 1824, p.1.

24 AGN, Sección República, Fondo Ministerio de Instrucción Pública, tomo 106, f.15r. (Santa Marta, 1824); Gaceta de Colombia, No. 115, diciembre 28 de 1823, p.1; n. ${ }^{\circ} 134$, mayo 5 de 1824, p.2.

25 Gaceta de Colombia n. $^{\circ} 120$, febrero $1^{\circ}$ de 1824 , p.1.

26 Sobre este tipo de propuestas ya existían antecedentes concretos a finales del periodo colonial En 1808, por ejemplo, el cartagenero don Manuel José Marín solicitó licencia para instalar una escuela pública de primeras letras en la villa de Mompós. Biblioteca Nacional de Colombia (BNC), Fondo Manuscritos, libro 338, ff.532-535.

27 “Aviso", en Gaceta de Cartagena de Colombia n. ${ }^{\circ} 179$, enero 15 de 1825, p.4. 
probada experiencia docente en las ciudades de Charleston y Kingston durante más de dos décadas con satisfacciones para los padres y resultados exitosos en los estudiantes. El precio de la matrícula era de un peso y otro al fin de mes por saber leer, dos por escribir y tres por los conocimientos elementales de aritmética. ${ }^{28}$

Los colegios de Santa Marta, Cartagena y Mompós, fundados entre 1824 y 1825 mediante sendos decretos dictados por el vicepresidente Santander, se constituyeron en un nuevo incentivo para los estudiantes de las escuelas elementales pues contaban ahora con mayores posibilidades de dar continuidad a sus estudios dentro del mismo marco regional y sin necesidad de tener que viajar hasta la ciudad de Bogotá.

Un tema de hondas implicaciones en materia de cobertura era la idea que se había planteado de comprometer a los padres a enviar sus hijos a la escuela. Sobre este punto en particular, la ley del 2 de agosto de 1821 resolvió que, siendo una prioridad el que todos los pequeños aprendieran los principios básicos del saber, los jueces debían formar un padrón de los niños de 6 a 12 años de edad, obligando a los padres que no se hubiesen decidido aún a remitir a sus hijos a la escuela en el término de un mes después de cumplida la edad necesaria o de haberse constituido este centro. Los omisos incurrirían en una multa de cuatro pesos que sería duplicada y aplicada para el fondo de la misma escuela si en el plazo adicional de 15 días no atendían el requerimiento. Únicamente serían exceptuados aquellos vecinos en estado de pobreza que viviesen distantes del pueblo. De todos modos, estas medidas de carácter coercitivo no eran impedimento para que los padres brindaran a sus hijos una instrucción privada o para que los ubicaran en el plantel de su preferencia. $^{29}$

El general Carlos Soublette, intendente del Magdalena, reiteró en el mes de abril de 1825 el llamado de cooperación a los padres de familia de la ciudad de Cartagena para que enviaran voluntariamente a sus vástagos mayores de siete años a la

\footnotetext{
28 “Aviso", en Gaceta de Cartagena de Colombia n. ${ }^{\circ}$ 189, marzo 26 de 1825, p.4.

29 Actas del Congreso de Cúcuta vol.II, pp.56-59, 159.
} 
escuela o, de lo contrario, las autoridades se verían obligadas a adoptar medidas rigurosas, tal como lo contemplaba la ley. ${ }^{30}$

\section{Celebración pública, Patria y educación}

Algunas fundaciones de escuelas se realizaron en medio de actos solemnes y en determinados casos coincidieron con fechas de celebraciones patrióticas, ${ }^{31}$ con lo cual se pretendía imprimir mayor realce a este tipo de acontecimientos y al mismo tiempo enviar un mensaje de estímulo a otras localidades con el fin de que se animaran a crear este tipo de establecimientos. Aquí la intención de fondo era entronizar en la comunidad las virtudes de los principios republicanos, asociándolos con el impulso de la cultura y la educación dentro de un nuevo modelo de nación.

El 17 de octubre de 1824 los habitantes de Ciénaga de Oro presenciaron la inauguración de la escuela elemental. La sede dispuesta para este plantel fue reacondicionada, blanqueada y decorada con las armas de la República que le imprimían el carácter de edificación nacional. Los reportes del evento permiten conocer los detalles del espacio donde los alumnos recibirían las clases: "Un salón de 24 varas de largo y 8 de ancho con 2 puertas y 12 ventanas, situadas en uno de los ángulos de la plaza, con su patio cercado y contenido catorce banquetas para asientos y un número suficiente de bancas para escribir”. ${ }^{32}$

En la víspera hubo iluminación general, regocijo y toda serie de diversiones populares. El día central de la inauguración comenzó con una misa solemne de acción de gracias a la que asistieron los vecinos más prestantes, el alcalde, el cura, el preceptor y los padres de familia. A las cuatro de la tarde, el resonar de cajas, el

30 "Educación pública", en Gaceta de Cartagena de Colombia n. ${ }^{\circ} 194$, abril 30 de 1825, p.4.

31 Sobre celebraciones patrióticas véase: Roger Pita Pico, “iVivas al Rey! Y ivivas a la Patria!: el influjo del ceremonial público en las provincias de Santa Marta y Cartagena en tiempos de la Independencia, 1808-1825”, en Memorias vol.11, n. ${ }^{\circ} 22$, Barranquilla, Universidad del Norte, 2014, pp.185-211.

32 "Provincia de Cartagena", en Gaceta de Cartagena de Colombia n. ${ }^{\circ} 175$, diciembre 18 de 1824, p.2. 
repique de campanas, la música y los tiros al aire, anunciaban el inicio de los actos de apertura. El cura bendijo el salón y luego el maestro inscribió en una tablilla especialmente dispuesta el nombre de los 140 educandos, cada uno de los cuales era presentado por su propio padre.

El alcalde José Penagos de Toledo pronunció unas palabras en las que hizo énfasis en la importancia de ser fieles a la Patria y de expresar gratitud al "gobierno paternal que se esfuerza en ilustrar a sus súbditos y hacerlos dignos ciudadanos”. Los padres de familia fueron exhortados a nunca dejar de enviar a sus hijos a clase ni faltar con el pago de la pensión asignada.

Posteriormente, intervino el cura a través de un elocuente discurso en el que reafirmó su indeclinable interés en el fomento de la educación desde la época de la represión española. Aprovechó además la oportunidad para rendir homenaje y gratitud a los máximos dirigentes políticos a nivel nacional y regional e invitó al estudiantado a ser aplicados, haciéndoles ver las necesidades y las ventajas de este proceso formativo básico. Para concluir, el religioso exclamó una emotiva arenga incitando a los alumnos a odiar al gobierno español que, según él, "siempre les había prohibido los medios de ilustrarse".

Culminada la ceremonia, al momento de abandonar el salón, se escucharon vivas a la República, al Libertador Presidente y demás jefes políticos, todo en medio de un nuevo estruendo de cajas, campanas y músicas. El cura repartió dinero al pueblo en tres ocasiones y a continuación convidó al pueblo a degustar de un refresco.

Una solemne función se preparó en la población de Turbaco el 5 de enero de 1825 para la apertura de la escuela primaria y a través de la prensa se reconocieron los "esfuerzos patrióticos" del alcalde Antonio Castañeda: "Si los magistrados a quienes la ley encarga la dirección y beneficio de las parroquias imitasen el celo del de Turbaco, la República cogería los frutos de la educación y de la libertad con abundancia y en poco tiempo". 33

33 “Departamento del Magdalena”, en Gaceta de Colombia n. ${ }^{\circ} 175$, febrero 20 de 1825, p.3. 
El espíritu de celebración pública cobijó también las actividades académicas. En el artículo $11^{\circ}$ del decreto del 6 de octubre de 1820 se dispuso que, cada cuatro meses bajo la presencia de las autoridades provinciales, el cura, los jueces del lugar y los escolares, se organizara un certamen sobre las materias cursadas para juzgar el nivel de aprendizaje. La ley del 2 de agosto del año siguiente dio continuidad a estos concursos con premios a manera de incentivos. Muchos de estos eventos fueron publicados en la prensa regional con el fin exaltar la evolución de los alumnos y del proyecto educativo en marcha.

La escuela de Simití que albergaba a más de 6o niños organizó el 10 de septiembre de 1823 un certamen público dedicado al vicepresidente Santander. La programación se abrió con una enérgica alocución del párroco Luis Serrano en la que puso de presente las ventajas de la ilustración gracias al apoyo e interés del gobierno. Con tan solo dos meses de principiadas las clases, los alumnos Antonio Pacheco, Prudencio Alcocer, José María Morillo, José María López, Félix Lemus y Rudecindo Pinto sorprendieron al público asistente tras haber respondido acertadamente el examen de ortografía y gramática, en razón a lo cual recibieron un premio del cabildo. Desde la distancia, el vicepresidente hizo llegar un mensaje de gratitud por este homenaje mientras que el preceptor, el presbítero José María Garrido, mereció elogios por su esmerada labor pedagógica. ${ }^{34}$

El 15 de septiembre del año siguiente se realizó el primer certamen público de la escuela lancasteriana de Cartagena. El acto fue presidido por el general de división e intendente del departamento del Magdalena, Carlos Soublette, y contó además con la asistencia del provisor gobernador del obispado, el asesor de intendencia, el director de estudios Ignacio Cavero, el director de la enseñanza mutua Pedro Comettan y los diputados.

Se procedió entonces a examinar a los alumnos en las materias de doctrina cristiana, derechos del hombre, principios de gramática, ortografía y aritmética. Conocidos los resultados, el intendente condecoró a los jóvenes Manuel Portillo, Julián Patricio Piñeres y Pedro Espinosa con un escudo de oro. En la octava clase fueron recompensados con ocho pesos Luis Guardiola de 12 años y Faustino Vásquez de 11 años por su aplicación y aprovechamiento mientras que Nicolás Jimé-

34 “Educación pública”, en Gaceta de Colombia n. ${ }^{\circ} 109$, noviembre 16 de 1823, p.3. 
nez, Pedro Imitola y Mateo Espinosa recibieron dos pesos cada uno. En la séptima clase fueron premiados con dos pesos Pedro Guzmán e Ildefonso Mora por su aplicación. La misma cantidad fue repartida entre cada monitor a manera de gratificación.

En su discurso, el director de la escuela fray Antonio María Dufort, religioso de la Orden de Predicadores, lamentó no haber presentado esta vez mayores progresos debido a la desconfianza que todavía sentían algunos padres de familia frente al nuevo método lancasteriano y al hecho de que muchos pequeños no habían vuelto tras ser requeridos para colaborar en las labores de subsistencia económica de sus hogares. Dufort lanzó un llamado a las autoridades locales para cooperar por la causa común de la educación y de antemano se comprometió a exhibir mayores adelantos en el próximo certamen público para así dejar sin argumentos válidos a los críticos y detractores del nuevo esquema de enseñanza mutua. Por último, expresó abiertamente sus deseos por la pronta visita del célebre José Lancaster, para que él mismo se cerciorara de los alcances de su novedoso método educativo. ${ }^{35}$

\section{Los entresijos de la financiación}

Las fuentes de financiación de la educación pública fue uno de los temas más álgidos de discusión durante la naciente República. Varias opciones de recursos públicos, privados y mixtos fueron analizadas al interior del gobierno y del Congreso ante el déficit de las arcas públicas, los crecidos gastos destinados a la guerra y el estado de desaceleración económica. Los saqueos, los embargos, los donativos, las contribuciones forzosas y la ruina provocada por la confrontación militar, eran factores que habían generado un impacto generalizado en la economía de esta región costera. El estado de abandono de las haciendas, el pálido comercio y la ausencia de una agricultura de exportación ahondaban aún más la crisis, todo esto con el agra-

35 “Escuela Normal”, en Gaceta de Cartagena de Colombia n. ${ }^{\circ} 163$, septiembre 25 de 1824, pp.1-2. 
vante de que buena parte de los esfuerzos aún se hallaban concentrados en el sector militar de defensa. ${ }^{36}$

La ley del 2 de agosto de 1821 promulgada por el Congreso de Cúcuta había ordenado que en todas las ciudades, villas y parroquias de más de 100 vecinos debía haber por lo menos una escuela de primeras letras. Las ciudades y villas sufragarían los gastos de dotación con los recursos de las rentas de propios ${ }^{37}$ pero allí donde estos recursos fueren insuficientes y, en las parroquias, había que recurrir a la solidaridad de los vecinos, comprometiéndose voluntariamente a efectuar los pagos mensuales. Si de este modo no se cubría la cantidad requerida para la escuela, las autoridades locales se encargarían de hacer un repartimiento "justo y moderado" teniendo en cuenta el patrimonio y número de hijos de cada vecino cabeza de familia. Esta lista cobijaba a los solteros y exceptuaba a los pobres, cuyos hijos accederían gratuitamente a la educación. Era también deber de los vecinos conseguir la sede para la escuela y los demás útiles indispensables. ${ }^{38}$

Una nueva alternativa de financiación propuso la ley del 28 de julio de 1821 al disponer que los fondos, bienes y edificios de los conventos suprimidos fueran invertidos en la educación pública. ${ }^{39}$ En respuesta a esto, la Intendencia del Magdalena recibió autorización del vicepresidente Santander para aplicar 10.00o pesos de rentas de los conventos suprimidos en Ocaña y su jurisdicción para el establecimiento de una escuela lancasteriana y el resto sería destinado para el colegio de Santa Marta. En Valledupar se aplicaron 9.000 pesos para instalar también una

36 Clément Thibaud, "Los aspectos sociales de la guerra por la Independencia en la Nueva Granada”, en 1810. Antecedentes, desarrollo y consecuencias, Bogotá, Ed. Taurus, 2010, pp.208-209. Se sabe por lo menos que en el año fiscal de 1825-1826, aproximadamente las tres cuartas partes de los gastos del Estado estaban enfocadas hacia el estamento militar. David Bushnell, El Régimen de Santander en la Gran Colombia, Bogotá, El Áncora, 1985, p.122.

37 Las rentas de propios eran las rentas oficiales a nivel municipal manejadas por los cabildos de cada localidad.

38 Actas del Congreso de Cúcuta vol.II, pp.48, 158.

39 Gazeta de la ciudad de Bogotá n. ${ }^{\circ}$ 125, Bogotá, diciembre 16 de 1821, p.403. 
escuela por el nuevo método que sería instalada en el edificio del convento que estuviese en mejores condiciones. ${ }^{40}$

Tal como lo reconoció el gobierno central, en los años siguientes el desarrollo de la educación básica fue muy lento debido a que los pueblos no podían soportar la carga de la contribución para las escuelas teniendo aún la responsabilidad de ayudar para la estabilidad y conservación de la independencia política alcanzada hacía poco. Ante la dificultad de recolectar las cuotas asignadas a los vecinos, había reportes que indicaban que algunos maestros perdían la paciencia y abandonaban la escuela. ${ }^{41}$

Era claro que el Estado central no estaba en capacidad de cubrir todas las necesidades a nivel regional. Por eso, en julio de 1824 se suscitó un álgido debate al interior del Senado de la República en relación con una propuesta que pretendía erigir una escuela en Riohacha con cargo a las rentas públicas nacionales en consideración a la situación deficitaria de esta ciudad costera luego de haber padecido un voraz incendio el 4 de junio de 1820.

Para este propósito, el gobierno central había solicitado sacar recursos de las rentas de los conventos suprimidos. No obstante, tal como lo informó Pedro Rodríguez, gobernador y comandante de armas de Riohacha, en esta ciudad no se contaban con estos fondos pues, si bien existía una capilla de los frailes dominicos desde los tiempos del dominio español, esta se hallaba en estado ruinoso y sus esquilmadas rentas habían sido remitidas en 1817 a Santa Marta. Algunas casas pertenecientes a esta comunidad religiosa quedaron prácticamente destruidas por el incendio. ${ }^{42}$

Varios congresistas advirtieron que no se podían fijar preferencias pues muchas otras poblaciones compartían también el anhelo de instalar una escuela con

40 José María Mier, La Gran Colombia, tomo I, Bogotá, Instituto Caro y Cuervo, 1983, pp.280-281.

41 José Manuel Restrepo, Exposición que el Secretario p.9; Luis López Domínguez (comp.), A los colombianos: proclamas y discursos, 1812-1840, Bogotá, Biblioteca de la Presidencia de la República, 1988, pp.191-193.

42 AGN, Sección República, Fondo Ministerio de Instrucción Pública, tomo 106, ff.18r.-19r. (Riohacha, 1824). 
los recursos del erario central. Especialmente, se temía que surgieran quejas y resentimientos en las localidades más pobres o en aquellas que habían dado muestras incuestionables de sacrificio por la Patria y la Independencia. Al final, se aprobó la proposición pero con la condición de que esta asignación se aplicara por el término de cinco años a menos de que antes la renta de propios alcanzara a cubrir este gasto. ${ }^{43}$ En desarrollo de esta decisión, se ordenó una partida inicial de 300 pesos. ${ }^{44}$

Las solicitudes de apoyo al gobierno central no cesaban. En abril de 1825, el gobernador de la provincia de Santa Marta, José Sardá, pidió al vicepresidente Santander asumir los costos de útiles y demás gastos para el establecimiento de la escuela lancasteriana en la ciudad de Ocaña. Esto en vista de que los aportes particulares eran muy exiguos y porque aún no podía disponerse de los recursos de los conventos suprimidos hasta tanto no se liberaran los créditos que recaían sobre esas rentas. La inquietud fue trasladada a la secretaría de Hacienda para que se giraran los recursos requeridos. La siguiente tabla relaciona los elementos que finalmente fueron traídos de Bogotá para ese propósito y cuyo costo total fue estimado en 95 pesos con 3 reales:

Tabla 1:

Útiles para el establecimiento de escuela lancasteriana en la ciudad de Ocaña en 1825

\begin{tabular}{|l|c|c|}
\hline \multicolumn{1}{|c|}{ Útiles } & No. & Valor \\
\hline Ejemplares del catecismo de Fleuri & 50 & 30 pesos \\
\hline Ejemplares de gramática castellana y ortografía & 50 & 25 pesos \\
\hline Catecismo añadido del Padre Astete & 50 & 12 pesos, 4 reales \\
\hline Ejemplares de cartillas antiguas & 50 & 4 pesos, 5 reales \\
\hline $\begin{array}{l}\text { Juegos de silabarios de lectura y aritmética impresos } \\
\text { y manuscritos }\end{array}$ & 2 & 9 pesos \\
\hline $\begin{array}{l}\text { Modelos o muestras impresas y manuscritas de caligrafía } \\
\text { de todos los tamaños }\end{array}$ & 70 & 8 pesos \\
\hline $\begin{array}{l}\text { Pizarras ordinarias sin marco, entre grandes y chicas } \\
\text { El cuaderno instructivo del nuevo método lancasteriano } \\
\text { manuscrito }\end{array}$ & 20 & 3 pesos, 2 reales \\
\hline
\end{tabular}

Fuente: AGN, Sección República, Fondo Ministerio de Instrucción Pública, tomo 106, f. $10 \mathrm{r}$.

43 Santander y el Congreso de 1824. Actas y correspondencia. Senado, vol.III, Bogotá, Biblioteca de la Presidencia de la República, 1989, pp.219-243.

44 Acuerdos del Consejo de Gobierno de la República de Colombia, 1821-1824, vol.I, Bogotá, Biblioteca de la Presidencia de la República, 1988, p.256. 
Aún faltaba por conseguir: 25 mesas, 25 bancas, una plataforma grande para el profesor y una pequeña para los monitores, 76 tablas para colgar alrededor del salón y fijar en ellas los silabarios de lectura y aritmética, 8 telégrafos ${ }^{45}$ para las 8 clases, 100 lapiceros, 1.000 lápices, 16 marcas de cuero curtido con su respectiva inscripción y 20 varitas o punteros con que los monitores indicaban la lección a los educandos. Se sugirió además reparar el reloj existente, ampliar el salón de clases para que pudiesen acomodar allí las 25 mesas de las 8 clases con el fin de cumplir fielmente las disposiciones del método y retirar los asientos fijos de material pues impedían formar los semicírculos de lectura y aritmética. Se propuso además asignar una cuota mensual para los billetes y recompensas que serían entregadas a los niños de sobresaliente comportamiento.

Ante la crisis fiscal imperante, los impuestos fueron fuentes de recursos de gran apoyo para el desarrollo de la educación básica. Las autoridades de la población de San Benito Abad propusieron en 1823 destinar parte del impuesto a la navegación y al comercio para el fomento de las escuelas. Ante el estado deficitario de las rentas locales y la pobreza del vecindario, la Junta curadora de educación pública de la parroquia de Arjona solicitó en septiembre de 1828 que el impuesto de policía que se exigía a razón de un real por cada arroba de la carne que se consumía, fuera invertido en el sostenimiento de la escuela en vista de que hasta ahora la comunidad no había visto ningún beneficio público de ese tributo. ${ }^{46}$

Otra alternativa de financiación fue el establecimiento de loterías. Debido a la insuficiencia de recursos en la renta de propios y al estado de crisis económica que impedía costear escuelas primarias y adelantar otras obras de beneficio público en el departamento del Magdalena, el intendente decidió mediante decreto del 26 de agosto de 1822 crear una lotería en la cual cada vecino contribuyera voluntariamente según sus capacidades y con el incentivo de participar en la rifa de los premios. Se tenía la convicción de que era necesario crear fortunas para superar el estado de desolación provocado por la guerra. La idea era recoger cada mes bajo esta fórmula 12.00o pesos en la provincia de Cartagena, 5.000 en la de Santa Marta y

45 Estos telégrafos eran unas tablas que indicaban el número de la clase.

46 AGN, Sección República, Ministerio de Instrucción Pública, tomo 109, ff.588r., 691r. (San Benito Abad, 1823). 
3.00o en la de Riohacha y, cada seis meses, sería recaudado el doble de esa cantidad para organizar un sorteo extraordinario. A través de este medio, los ciudadanos podían rifar propiedades y alhajas cuyo valor fuera superior a 1.000 pesos. ${ }^{47}$

Las donaciones fueron otra opción altamente estimada por el gobierno y una muestra del espíritu de solidaridad de la comunidad en procura de la causa de la educación. La fundación de la escuela de Ciénaga de Oro se debió en gran medida a la persistente gestión adelantada por el cura de esta parroquia. Fue él quien convenció a los vecinos para que cooperaran con la construcción del salón de clases con aportes de 2 pesos mensuales, figurando él mismo en la cabeza de esta lista. A manera de precedente, entregó una donación de 25 pesos, aparte de lo que había proveído en materiales y útiles necesarios para la obra. No contento con esto, patrocinó además la beca de 13 niños pobres y en el acto de apertura regaló a todos los alumnos los libros y cartillas para el aprendizaje básico. ${ }^{48}$

Hacia 1823 el presbítero de la población de Lorica, Tomás de la Cruz Gómez, dejó antes de morir un capital de 4.000 pesos para ser destinado al sostenimiento del maestro de la escuela de esta localidad, con lo cual quedaba aliviada la carga que significaba para los vecinos el pago de la cuota mensual. La escuela de Ocaña se vio también favorecida por un cura benefactor, el presbítero Diego Gabino Quintero, de cuyos bienes mortuorios se destinaban 50 pesos anuales para pagarle al maestro. 49

También se pensó en la viabilidad de contar con la asesoría y el respaldo de las sociedades de carácter privado en momentos en que apenas se estaban cimentando las bases de las instituciones públicas. En la Constitución del Estado de Cartagena de Indias promulgada en 1812, el gobierno brindó todo su respaldo a la $\mathrm{So-}$

\footnotetext{
47 AGN, Sección República, Ministerio de Instrucción Pública, tomo 109, ff.645r.-646r. (Cartagena, 1822).

48 "Provincia de Cartagena”, en Gaceta de Cartagena de Colombia n. ${ }^{\circ} 175$, diciembre 18 de 1824 , p.3.

49 AGN, Sección República, Ministerio de Instrucción Pública, tomo 109, ff.689r, 697r. (Ocaña, 1823).
} 
ciedad patriótica de amigos del país ${ }^{50}$ existente en la capital de esta provincia, y dio todo su aval para que esta institución patrocinara y fomentara la educación a través de la fundación y vigilancia de las escuelas para ambos sexos "como uno de los mayores servicios que puede hacer a la República”. ${ }^{51}$

A finales de 1825, el gobierno central expresó su beneplácito por la creación de la Sociedad de Amigos de la instrucción elemental en la ciudad de Mompós, cuyo reto era crear una escuela lancasteriana anexa al colegio Pinillos sobre la base de que la enseñanza pública era "la piedra angular del edificio nacional" y, por consiguiente, era deber de cada ciudadano sumarse a esa causa. También se propuso el fomento de las escuelas privadas que beneficiarían de manera especial a quienes se les dificultaba asistir a la escuela lancasteriana.

Esta Sociedad estaba conformada por personas respetables, interesadas en trabajar mancomunadamente con la autoridad pública y los sectores vivos del municipio. Dentro de los amigos socios de número figuraban: su presidente el presbítero Luis José Serrano, el cura vicario Januario Aguilar, el presbítero Gregorio Asís, Nicomedes Flórez, Francisco Trespalacios, Tomás Ribón, Marcelino Pinillos, Bernabé Noguera, Marcelino Echávez, José María Pino, Vicente Vargas y Tomás Choperena. Algunas damas prestantes también mostraron interés en vincularse.

Desde las páginas de la prensa oficial, se elevó una invitación a las demás ciudades para que imitaran este tipo de iniciativas en beneficio de la educación, entendida como la "base del sistema político y fuente de la felicidad común". ${ }^{52}$ Una de las primeras ejecutorias de esta Sociedad consistió en costear de sus fondos al maestro de primeras letras de esta ciudad y a uno de los estudiantes del colegio pa-

50 Las sociedades patrióticas o también conocidas como sociedades de amigos del país, eran instituciones similares a las existentes en Francia, Inglaterra y España, cuyo propósito era promover los adelantos en la agricultura, el comercio y la educación. Margarita Garrido, Reclamos y Representaciones: variaciones sobre la política en el Nuevo Reino de Granada, 1770-1815, Bogotá, Banco de la República, 1993, p.67.

51 Constitución del Estado de Cartagena, p.113.

52 “Sociedades", en Gaceta de Colombia n. ${ }^{\circ} 220$, enero $1^{\circ}$ de 1826, p.3. 
ra que se instruyeran en el método lancasteriano a fin de que lo transmitieran a los demás pueblos del cantón. 53

En marzo de 1827 la Sociedad solicitó formalmente al ejecutivo nacional colaboración para entablar contactos directos con el Consejo de Administración de la Sociedad de instrucción elemental de París, instancia que ya había expresado en Londres a la delegación colombiana su interés en promover y apoyar activamente la dotación de escuelas lancasterianas en los Estados americanos. El secretario del Interior José Manuel Restrepo recibió con beneplácito esta iniciativa de carácter internacional para la cual dio su correspondiente aval. Dentro de los benefactores de la Sociedad momposina inscritos este año se hallaba Pedro Gual, ministro plenipotenciario de Colombia en el Congreso de Panamá. 54

\section{Maestros: calidades y remuneración}

La falta de educadores y la preocupación por sus calidades fueron dos desafíos importantes durante los primeros años de implementación de las escuelas en tiempos de la Segunda República. La ley del 2 de agosto de 1821 dispuso que el gobernador de provincia era el encargado de nombrar a los maestros, para lo cual los cabildos o juntas especiales debían presentar una terna. Los candidatos debían ser examinados por una comisión nombrada por cada municipalidad. ${ }^{55}$

Aún en 1823 el secretario del Interior José Manuel Restrepo se mostraba preocupado por la falta de docentes, problema que según él era resultado de la ignorancia en que habían estado sumidos los pueblos bajo el sistema colonial. Él esperaba que con el tiempo y la buena gestión del gobierno republicano se difundieran las luces hasta el punto de que en la más remota de las parroquias existiera un

53 Gaceta de Cartagena de Colombia n. ${ }^{\circ} 230$, enero 14 de 1826, p.4.

54 AGN, Sección República, Ministerio de Instrucción Pública, tomo 109, ff.595r.-602v. (Cartagena, 1827).

55 Actas del Congreso de Cúcuta vol.II, p.159. 
ciudadano capaz de enseñar a los niños a leer, escribir y contar "con mediana perfección”. 56

La búsqueda se tornaba más complicada en aquellos pueblos apartados de la región. Si se registraban algunos tropiezos para ubicar maestros en las escuelas del método antiguo, mucho más arduo resultó el reto para conseguir educadores que dominaran el nuevo sistema de enseñanza mutua. Así por ejemplo, en mayo de 1823 la ciudad de Valledupar no contaba aún con escuela por falta de maestro. ${ }^{57}$ No hay que olvidar que el método lancasteriano causó cierta desconfianza en los padres de familia y por eso fue indispensable redoblar los esfuerzos para cumplir con las expectativas planteadas en materia de cobertura.

Un decreto promulgado el 26 de enero de 1822 dispuso que primero se fundaran escuelas lancasterianas en las ciudades de Bogotá, Caracas y Quito. Una vez desarrollada esta primera fase, fueron expedidas órdenes a los intendentes de los departamentos de Cundinamarca, Boyacá, Magdalena, Cauca e Istmo de Panamá para que cada una de las provincias instruyera jóvenes en el nuevo método. Adquirida la capacitación y aprobado el respectivo examen, estos jóvenes debían convertirse en difusores del método a los maestros de las parroquias, quienes para el efecto debían viajar hasta la capital de cada provincia. En este caso la prioridad la tendrían las parroquias más cercanas y populosas. Durante el tiempo de capacitación, los maestros seguirían gozando del sueldo que se les tenía asignados y, si esto no fuese suficiente, los padres de familia debían realizar una recolecta para asegurarles el hospedaje y la alimentación. ${ }^{58}$ Adicionalmente, el juez político de cada localidad debía acordar con estos maestros la persona que los reemplazarían gratuitamente durante el corto tiempo que duraba la capacitación. ${ }^{59}$

56 José Manuel Restrepo, Memoria que el secretario de Estado y del despacho del Interior presentó al Congreso de Colombia sobre los negocios de su Departamento, Bogotá, Imprenta de Espinosa, 1823, pp.26-27.

57 AGN, Sección República, Ministerio de Instrucción Pública, tomo 109, f.699r (Valledupar, 1823).

58 El Eco de Antioquia n. ${ }^{\circ}$ 2, Medellín, Imprenta del Gobierno por Manuel María Viller-Calderón, mayo 12 de 1822, p.6.

59 "Circular a los jueces políticos de esta provincia", en Gaceta de Cartagena de Colombia n. ${ }^{\circ} 207$, julio 30 de 1825 , p.3. 
Para tener éxito en este proceso de selección y preparación de maestros, había que recurrir a las alternativas de difusión disponibles. La municipalidad de Riohacha publicó el 11 de diciembre de 1824 un aviso en la Gaceta de Cartagena de Colombia invitando a aquellos interesados en participar en el proceso de selección de maestros para la escuela elemental lancasteriana, ofreciéndole al escogido un sueldo de 40 pesos mensuales. ${ }^{60} \mathrm{Al}$ parecer, el maestro solo desarrolló su oficio un año pues a finales de 1825 fue necesario preparar a nivel municipal una nueva convocatoria pero, en vista de que no se presentó ningún candidato que manejara el nuevo método, el intendente ordenó un aviso en la prensa regional para poder llenar esa vacante. ${ }^{61}$

A mediados de junio de 1824 Pedro Comettan, el encargado por el gobierno central para implementar el método lancasteriano, llegó a Colombia procedente de Caracas y Maracaibo con el objeto de enseñar este nuevo sistema tanto en la ciudad de Santa Marta como a los maestros destinados en Ocaña y Valledupar. Con el fin de agilizar la capacitación, Comettan solicitó al secretario del Interior el envío de una docena de ejemplares del manual de instrucción impreso en Bogotá pues hasta ahora solo se había valido de unas cuantas cartillas que eran muy útiles para enseñar el método a los profesores pero resultaban insuficientes para difundirlo entre los alumnos. El Padre fray José María Gerardino, designado en la ciudad de Ocaña para aprender el método, pidió autorización para recibir la instrucción en Bogotá pues se le facilitaba más trasladarse hasta esta capital con sus propios recursos y con el compromiso adicional de traer de allí los útiles para la nueva escuela. ${ }^{62}$

El general Carlos Soublette, intendente del Magdalena, exaltó en abril de 1825 las bondades de las escuelas lancasterianas y puso además de presente su carácter igualitario por cuanto allí eran admitidos ricos y pobres sin ninguna distinción. Para ser más explícito en sus argumentos, el mandatario regional hizo un parangón entre este modelo educativo y el de una nación republicana: “[...] confundidos todos los niños bajo un reglamento que les sirve de norma, no se castiga por

60 “Aviso", en Gaceta de Cartagena de Colombia n. ${ }^{\circ}{ }^{174}$, diciembre 11 de 1824 , p.1.

61 “Aviso”, en Gaceta de Cartagena de Colombia n. ${ }^{\circ} 229$, enero 7 de 1826, p.4.

62 AGN, Sección República, Fondo Ministerio de Instrucción Pública, tomo 106, ff.2r.-6r. (Ocaña, 1824). 
capricho ni mal humor, se premia el mérito y se confían los empleos a los más aptos que hayan mostrado más aplicación y más amor a la justicia”. ${ }^{63}$ Se anunció que en las horas de la mañana del 2 de mayo venidero Pedro Comettan estaría presente en la escuela anexa al colegio de la ciudad de Cartagena para inscribir allí a los interesados en ingresar a estas aulas.

Los procesos de selección de maestros no estuvieron exentos de controversias e irregularidades. A principios de marzo de 1825, el gobernador de Riohacha, el coronel José Sardá, postuló al ciudadano José María Pacheco como candidato de acuerdo con los procedimientos estipulados en la ley del 2 de agosto de 1821. La municipalidad designó una comisión encargada de examinar al aspirante en mención y del dictamen final se dedujo que leía mal, era principiante en el arte de la escritura, tenía fallas protuberantes en ortografía y adolecía de la suficiente capacidad para enseñar doctrina religiosa y derechos ciudadanos. Esta decisión desató en el candidato una andanada de críticas y señalamientos contra los examinadores mientras que uno de estos, J. María Cataño, envió una comunicación a la Gaceta de Cartagena de Colombia en la que ratificaba el consenso que había primado al interior de la comisión al concluir que Pacheco no servía "ni para escribiente". Cataño rescató las buenas intenciones del gobernador Sardá aunque tenía la convicción de que este funcionario había sido engañado por la persona que le recomendó a Pacheco. 64

Ese mismo año, el juez político de Sitionuevo se mostró preocupado al no ver en su jurisdicción un candidato que se ajustara a los requisitos mínimos para ser maestro pues en esa localidad solo cuatro personas sabían firmar su nombre. Al final, fue nombrado en ese cargo Domingo Valle pero inmediatamente el juez político impugnó ante el gobernador esta designación pues consideraba que él no reunía las calidades morales por vivir en constante estado de embriaguez. Ante la escasez de opciones para llenar esa vacante, el cura debió cumplir provisionalmente las funciones de maestro. 65

\footnotetext{
63 “Educación pública”, en Gaceta de Cartagena de Colombia n. ${ }^{\circ} 194$, abril 30 de 1825, p.4.

${ }^{64}$ Gaceta de Cartagena de Colombia n. ${ }^{\circ} 187$, marzo 12 de 1825, p.4.

${ }^{65}$ Steinar A. Saether, Identidades e Independencia en Santa Marta y Riohacha, 1750-185o, Bogotá, Icanh, 2005, p.227.
} 
La remuneración a los maestros no era un asunto meramente económico pues también trascendía al ámbito de la calidad educativa. Ya el vicepresidente Santander había advertido que, entre mayor era el sueldo, mejor debía ser el desempeño del educador. ${ }^{66}$ Según el decreto dictado por este alto funcionario en 1820, los gobernadores debían asignar los sueldos de los educadores según la disponibilidad de sobrantes de las rentas de propios, una vez satisfechos los pagos comunes. ${ }^{67}$ La ley del 2 de agosto de 1821 resolvió que el sueldo de los maestros debía ser proporcional a la cantidad de habitantes y riqueza de cada población. ${ }^{6}$

En los informes recogidos en octubre de 1823 por la intendencia del Magdalena se pueden advertir diversas fórmulas y alternativas de financiación para el pago de los maestros. Fray Nicolás Ruiz, profesor de la escuela lancasteriana de Cartagena, recibía 50 pesos mensuales de la renta de propios mientras que al de la escuela lancasteriana de Mompós se le asignaban 300 pesos anuales. Al maestro de la escuela existente en Barranquilla aún no se le había girado el primer pago por falta de cursos y en la escuela de Santa Marta su profesor recibía 360 pesos anuales gracias a la contribución de los vecinos pues por esa época las arcas locales se hallaban vacías. ${ }^{69}$

Hacia 1824, durante el proceso de selección del maestro de la escuela de la villa de Soledad, se ofrecieron 300 pesos de sueldo y adicionalmente se les informó sobre el incentivo de contar con una habitación en la casa destinada para este centro educativo..$^{70}$ La profesora de escuela para niñas de la ciudad de Santa Marta se lamentó al año siguiente de las dificultades que debía enfrentar para transmitir conocimientos a más de 70 alumnas registradas en su clase, además de que solo se le había pagado una mínima parte del sueldo anual prometido de 100 pesos. $^{71}$

\footnotetext{
66 Felipe Osorio Racines, Decretos del General Santander, p.154.

67 Felipe Osorio Racines, Decretos del General Santander, p.154.

68 Actas del Congreso de Cúcuta vol.II, p.159.

69 AGN, Sección República, Fondo Ministerio de Instrucción Pública, tomo 109, ff.675r.-701v. (Cartagena, 1823).

70 “Aviso al público”, en Gaceta de Cartagena de Colombia n. ${ }^{\circ} 157$, agosto 14 de 1824, p.4.

71 S. Saether, Identidades e Independencia, p.227.
} 


\section{Escuelas para niñas}

En el periodo de dominio hispánico, muy poca atención se le brindó al género femenino en materia educativa, procurándose siempre la separación de espacios y aulas para uno u otro género. Únicamente aquellas jóvenes más prestantes recibieron una instrucción rudimentaria que implicaba no solo leer, escribir y contar sino también desarrollar destrezas en oficios propios del bello sexo, tales como: coser, tejer y rezar. Los conventos de religiosas eran los escenarios predilectos para impartir estas enseñanzas.

El cambio de gobierno fraguado en 1819 no implicó automáticamente una transformación sustancial en la mentalidad de los ciudadanos y es por eso que muchos sectores aún defendían la estructura anquilosada del antiguo régimen de dominación colonial, con todas sus inequidades y segregaciones producto de la rígida estructura social. Así entonces, el género, la raza y la condición socio-económica seguían siendo factores evidentes de exclusión en materia educativa.

En vista de que había primado el énfasis en la educación para varones, una de las preocupaciones del naciente gobierno republicano fue diseñar una política educativa incluyente que les permitiera a las mujeres desarrollar un papel más activo en la sociedad. Para el presidente Simón Bolívar, la formación de las niñas era el eje nodal de la educación de la familia. ${ }^{72}$

Con base en el antecedente de la normativa española, el 28 de julio de 1821 se aprobó la fundación de escuelas para niñas en los conventos de religiosas pero con una mayor intervención estatal. Para ello, el poder ejecutivo debía acordar con los arzobispos y obispos el funcionamiento, el reglamento y el manejo administrativo de estos establecimientos en servicio "a Dios y a la Patria". ${ }^{73}$

72 Ana Neissa de Mantilla, La evolución del pensamiento educativo de Simón Bolívar. Principios vigentes en los modelos pedagógicos del tercer milenio, Bogotá, Gente Nueva Editorial, 2005, p.113.

73 Actas del Congreso de Cúcuta vol.II, p.124. 
De manera paralela, en la ley que a la semana siguiente expidiera el máximo órgano legislativo para la fundación de escuelas públicas para niños, se incluyó en el artículo $17^{\circ}$ una serie de disposiciones para el fomento de la educación femenina a través de una fórmula que combinaba la iniciativa ciudadana y el apoyo oficial a escala local. Le fue concedida la facultad al poder ejecutivo para fundar estas escuelas bajo el patrocinio de los vecinos o por otras instancias en las cabeceras de los cantones y demás parroquias en que fuere posible. En estos establecimientos las pequeñas debían aprender los principios morales y religiosos pero además debían cultivar el arte de coser y bordar. ${ }^{74}$

Aún con estas intenciones y avances normativos, todo indica que las oportunidades de acceso a la educación básica seguían registrando un profundo desbalance en materia de género. El propio Congreso de la República era consciente de que la educación de las niñas y jóvenes exigía "poderosamente" la protección estatal pero al mismo tiempo se advertía que la situación coyuntural de guerra y desolación hacía imposible proporcionar los medios indispensables para su fomento. Es por ello que no resulta difícil advertir cómo la primera preocupación oficial era asegurarles a los niños educación y luego, si había disponibilidad de recursos, se procedía a planear la instalación de escuelas para el género femenino.

En el mes de junio de 1822 fue instalada en la ciudad de Santa Marta, gracias al aporte mancomunado de los vecinos, una escuela de niñas en el convento de San Francisco, designándose como maestra a María Francisca Barranco. Pero, debido a los efectos del conflicto político y militar, este establecimiento solo funcionó hasta el 3 de enero del año siguiente cuando entraron los "facciosos" de Ciénaga e invadieron la ciudad. Muchos vecinos migraron y ya no fue posible conseguir fondos para el pago de la maestra. Tampoco existía la opción de lograr recursos de la renta de propios por el déficit fiscal imperante. ${ }^{75}$

En el balance de la gestión adelantada en 1822, el gobierno reconoció que la falta de fondos había impedido multiplicar las escuelas elementales para niñas, lo que a su vez había entorpecido la misión pedagógica encomendada a los conventos

74 "Congreso", en Gazeta de Santa Marta n. ${ }^{\circ} 24$, octubre 20 de 1821, p.90; AGN, Sección República, Fondo Ministerio de Instrucción Pública, tomo 109, ff.675r.-696r. (Bogotá, 1824).

75 AGN, Sección República, Fondo Ministerio de Instrucción Pública, tomo 109, f.696r. 
de monjas, de conformidad con la ley del 28 de julio de 1821 . La queja argüida por las religiosas era que carecían de recursos para construir una sala especial para la enseñanza de las estudiantes mientras que el poder ejecutivo admitía que no podía destinar fondos públicos del orden nacional para gastos de esta índole. Ante esto, el secretario del Interior don José Manuel Restrepo elevó un llamado al Congreso para gestionar algunas rentas dirigidas a subsanar ese vacío. ${ }^{76}$

Muy contadas también eran las instituciones de carácter privado existentes durante esta época y estas casi siempre respondían al interés de algunas extranjeras y damas prestantes. Madame Cavalier instaló a mediados de 1823 en la ciudad de Cartagena un establecimiento de educación para niñas con el lema de instruirlas en el ejercicio de la religión católica y la práctica de una sana moral "[...] habituándolas a los pequeños oficios domésticos necesarios a una ama de casa y madre de familia". ${ }^{77}$ Además, se les enseñaría a leer en francés y español, escribir, recitar algunas fábulas, y a tejer medias y encajes. La casa de educación se responsabilizó en mantener a su costa un maestro de lengua castellana para pensionadas y externas. Para la enseñanza se seleccionaron libros de instrucción religiosa, obras clásicas de ilustración y textos de diversión para ejercitar la memoria. Era opción de los padres que sus hijas recibieran clases de piano y música vocal, para lo cual debían sufragar una cuota adicional de 8 pesos.

Las niñas que estaban bajo la modalidad de pensión no podían estar por debajo de los ocho años y debían pagar sus padres 20 pesos anuales. Era responsabilidad de los acudientes suministrarles a estas "pensionistas" un catre, un colchón, una almohada, tres pares de sábanas, seis servilletas, un cubierto y un vaso de plata "a fin de mantenerlo con el mayor aseo". También debían proveerles libros, papel, plumas, tinta, música y asegurarles el lavado de ropa.

El costo de los estudios para las niñas externas, cuya edad no podía ser superior a ocho años, sería de dos pesos mensuales. Cada una de estas pequeñas debía traer silla, libros, papel, pluma, hilo, agujas y todo lo indispensable para sus actividades curriculares a fin de evitarles el tener que realizar al mediodía "viajes moles-

76 J. M. Restrepo, Memoria que el secretario, pp.26-27.

77 “Aviso al público", en Gaceta de Cartagena de Colombia n. ${ }^{\circ} 94$, julio 5 de 1823, p.394. 
tos" hasta sus casas. De sus hogares podían enviarles diariamente los alimentos a la escuela donde además las niñas aprenderían a comer apropiadamente y a comportarse en la mesa.

El menú del desayuno para las "pensionistas" consistía en frutas, chocolate y café o leche, "según el deseo de sus padres". Al mediodía, a la hora del almuerzo recibían "comida de sopa, olla, principio o un asado y un plato de legumbres". En los días de pescado se les ofrecía sopa, un plato de huevos o de pescado, legumbres y ensalada. A las cuatro de la tarde recibían de merienda un pedazo de pan y queso y a las siete de la noche se servía la cena en la cual podían degustar un plato de legumbres, una ensalada y frutas.

\section{Conclusiones}

En los primeros años de Colombia como nación independiente, los dirigentes republicanos concibieron la educación como un factor de cohesión y unidad política en torno a instituciones recientemente constituidas con base en los principios liberales. ${ }^{78}$

El gobierno central buscó legitimarse a nivel provincial a través de la iniciativa de fundar escuelas y colegios como mecanismo para acceder al progreso y la felicidad. Envió con ello un mensaje de unidad clave en este proceso de formación nacional.

Fue claro además el interés del Estado republicano en plantear su disposición de establecer una participación y una vigilancia más directa en el nivel de educación básica que desde tiempo atrás había recibido gran influencia de la Iglesia. A pesar de esto, los curas siguieron manteniendo su papel de liderazgo en este proceso.

Los ambiciosos planes en cobertura de educación primaria en la costa Caribe se tropezaron con un ambiente hostil signado por la crisis económica, el déficit fis-

78 Jesús Echeverri Sánchez, Proceso de constitución de la instrucción pública 1819-1835, Medellín, Universidad de Antioquia, 1984, pp.27-28. 
cal y la tensión político-militar en medio de una frágil y fluctuante estructura administrativa. Esta situación conllevó a las autoridades regionales a tener que ingeniarse nuevas y variadas fórmulas de financiación, lo cual implicó un apoyo y un compromiso más activo por parte de la comunidad y de las instancias de gobierno a escala local.

En realidad, faltaba todavía mucho trecho para garantizar una educación incluyente que estuviese en sintonía con los principios de igualdad y libertad pregonados insistentemente por el proyecto republicano. Debieron pasar varias décadas para que finalmente se cerrara la brecha en las oportunidades de acceso educativo para el género femenino.

Aún con todas las dificultades y deficiencias, no hay que desconocer el gran impulso que le imprimió el vicepresidente Santander y las autoridades regionales al proyecto educativo en marcha que se vio complementado con la creación de la escuela náutica en la ciudad de Cartagena ${ }^{79}$ y la instalación de escuelas de oficios artesanales, establecimientos estos que contribuyeron al proceso de recuperación económica de las provincias de la costa Caribe colombiana que habían resultado devastadas por las guerras de Independencia.

\section{Bibliografía}

\section{Fuentes primarias de archivo}

Archivo General de la Nación (Bogotá, Colombia) (AGN), Sección República, Ministerio de Instrucción Pública.

Biblioteca Nacional de Colombia (Bogotá, Colombia) (BNC), Fondo Manuscritos.

\section{Prensa}

El Eco de Antioquia, Medellín, Imprenta del Gobierno por Manuel María Viller-Calderón, 1822.

79 Esta escuela fue creada en Cartagena por el vicepresidente Santander el 28 de junio de 1822. Gaceta de Colombia n. ${ }^{\circ}$ 39, junio 14 de 1822, p.3. 
Gaceta de Cartagena de Colombia, Cartagena, Imprenta del Gobierno por Juan Antonio Calvo, 1824-1826.

Gaceta de Colombia, Bogotá, Imprenta de Espinosa, 1822-1826.

Gazeta de la ciudad de Bogotá, Bogotá, Imprenta del Estado por Nicomedes Lora, 1821.

Gazeta de Santa Marta, Santa Marta, Imprenta del seminario por Tadeo Rodríguez, 1821.

\section{Fuentes primarias impresas}

Actas del Congreso de Cúcuta, 1821, vol.II, Bogotá, Biblioteca de la Presidencia de la República, 1990.

Acuerdos del Consejo de Gobierno de la República de Colombia, 1821-1824, vol.I, Bogotá, Biblioteca de la Presidencia de la República, 1988.

Constitución de la República de Colombia, Rosario de Cúcuta, Bruno Espinosa, Impresor del Gobierno General, 1821.

Constitución del Estado de Cartagena de Indias, Cartagena de Indias, Imprenta del Ciudadano Diego Espinosa, 1812.

López Domínguez, Luis (comp.), Obra educativa de Santander 1819-1826, vol.I. Bogotá, Biblioteca de la Presidencia de la República, 1990,

López Domínguez, Luis (comp.), A los colombianos: proclamas y discursos, 1812-1840, Bogotá, Biblioteca de la Presidencia de la República, 1988.

Mier, José María, La Gran Colombia, tomo 1,Bogotá, Instituto Caro y Cuervo, 1983.

Osorio Racines, Felipe, Decretos del General Santander. 1819-1821, Bogotá, Universidad Nacional, 1969.

Osorio, Alejandro y Vergara, Estanislao, Los encargados de la Secretaría General del Departamento de Cundinamarca presentan a S. E. el General F. de P. Santander, vicepresidente del mismo Departamento, la memoria correspondiente al año de 1820, Bogotá, Imprenta de Espinosa, 1821.

Restrepo, José Manuel, Memoria que el secretario de Estado y del despacho del Interior presentó al Congreso de Colombia sobre los negocios de su Departamento, Bogotá, Imprenta de Espinosa, 1823.

Santander y el Congreso de 1824. Actas y correspondencia. Senado, vol.III, Bogotá, Biblioteca de la Presidencia de la República, 1989. 


\section{Fuentes secundarias}

Acevedo Puello, Rafael, "La historia y la patria en la provincia de Cartagena, 1810-1814. Apuntes sobre la noción de usos públicos de la historia”, en Memoria y Sociedad vol.14, n. ${ }^{\circ}$ 29, Bogotá, Pontificia Universidad Javeriana, 2010, pp.7-23.

Acevedo Puello, Rafael, "Escuelas y políticas educativas en la provincia de Cartagena entre 1903-1919”, en El Taller de la Historia vol.3, n. ${ }^{\circ}$, Cartagena, Universidad de Cartagena, 2011, pp.110-135.

Ahern, Evelyn, "El desarrollo de la educación en Colombia: 1820-1850", en Revista Colombiana de Educación n. ${ }^{\circ}$ 22-23, Bogotá, Universidad Pedagógica Nacional, 1991, pp.5-88.

Alarcón Meneses, Luis, "Maestros y escuelas normales en el Caribe colombiano durante el régimen federal", en Revista Historia de la Educación Latinoamericana vol.14, n. ${ }^{\circ}$ 18, Tunja, Universidad Pedagógica y Tecnológica de Colombia, 2012, pp.155-182.

Bushnell, David, El Régimen de Santander en la Gran Colombia, Bogotá, El Áncora, 1985.

Echeverri Sánchez, Jesús, Proceso de constitución de la instrucción pública 1819-1835, Medellín, Universidad de Antioquia, 1984.

Garrido, Margarita, Reclamos y Representaciones: variaciones sobre la política en el Nuevo Reino de Granada, 1770-1815, Bogotá, Banco de la República, 1993.

Neissa de Mantilla, Ana, La evolución del pensamiento educativo de Simón Bolívar. Principios vigentes en los modelos pedagógicos del tercer milenio, Bogotá, Gente Nueva Editorial, 2005.

Pita Pico, Roger, “iVivas al Rey! Y ivivas a la Patria!: el influjo del ceremonial público en las provincias de Santa Marta y Cartagena en tiempos de la Independencia, 18081825", en Memorias vol.11, n. ${ }^{\circ}$ 22, Barranquilla, Universidad del Norte, 2014, pp.185-211.

Rinaldy, Ángel, "Nación moderna: ciudadanos letrados. El compromiso de la élite cartagenera en la educación popular durante la República 1820-1840", en Historia Caribe vol.VI, n. ${ }^{\circ}$ 19, Barranquilla, Universidad del Atlántico, 2011, pp.153-175.

Sanabria Munévar, Francisco, "Enseñando mutuamente: una aproximación al método lancasteriano y a su aprobación en Colombia”, en Revista Historia de la Educación Colombiana vol.13, n. ${ }^{\circ} 13$, Pasto, Rudecolombia, 2010, pp.47-76.

Saether, Steinar, Identidades e Independencia en Santa Marta y Riohacha, 1750-1850, Bogotá, Icanh, 2005.

Thibaud, Clément, "Los aspectos sociales de la guerra por la Independencia en la Nueva Granada”, en 1810. Antecedentes, desarrollo y consecuencias, Bogotá, Editorial Taurus, 2010. 
Tranck de Estrada, Dorothy, "Las escuelas lancasterianas en la ciudad de México", en $L a$ educación en la historia de México, México, El Colegio de México, 1992, pp.49-68. 